\title{
Coping with new challenges in water resources management in Bangladesh
}

\author{
Md.Shahadat Hossain ${ }^{a^{*}}$ \\ Musfiqur Rahman ${ }^{\mathrm{a}}$ \\ Mir.Md.Tamim ${ }^{\mathrm{b}}$
}

\begin{abstract}
One of the most stressed resources in Bangladesh is water. Major challenges facing sustainable water resources management in the country today include: increasing vulnerability to extreme events, unrestricted extractions, growing urban demand, climate change, land-use changes and environmental requirements. In this context, the study gives an overview of existing water management practices in the country; and elucidates the role of hydrological services including focused Research and development (R\&D) in resolving water resources issues. A recent effort in enhancing institutional capacity for decision making is elaborated in the context of implementation of various Hydrology Projects. R\&D efforts in water sector are shown to embrace two major roles in furthering sustainable water resources management: i) helping to decrease the vulnerability by furthering development and increasing adaptive capacity, and ii) giving an option to respond to numerous contingencies that an unknown future holds.
\end{abstract}

\section{Key words: Water resources problems; WR engineering; Hydrology of Bangladesh.}

\section{Introduction}

At the beginning of $20^{\text {th }}$ century, the population of Bangladesh was approximately 3 crore; which rose to 14 crore at the beginning of $21^{\text {st }}$ century, and to about 16 crore today. With the growth of human population has come the increased need for resources to sustain the multitude. Food and water are two of the basic human needs; and the latter, in the form of irrigation, is necessary to produce much of the former. As world population increases, a catastrophe as predicted by many thinkers may or may not befall on the human race, but one thing is certain: what we get would be increasingly difficult choices, especially as regards water resources management, which can only be dealt effectively by the best available technology. Modern technology has contributed immensely to the sustenance of population of the country at present level.

\footnotetext{
a Institute of Water Modelling (IWM), New DOHS, Mohakhali, Dhaka-1206, Bangladesh

b Department of Civil Engineering, Southern University Bangladesh, Mehedibagh Road, Chittagong, Bangladesh

*Corresponding author: Md.Shahadat Hossain shn@iwmbd.org http://dx.doi.org/10.14453/isngi2013.proc.24
} 
Issues such as climate change, land-use changes, growing urban demand and environmental requirements continue to influence adversely sustainable water resources development and management. Research and development (R\&D), often referred as the engine of prosperity, provides the underpinning for use of best available technology in water sector, and optimum use of available resources. It can safely be said that the one and only way to circumvent waterrelated issues is manifold increase in technical innovation to facilitate optimum utilization of scarce resources; which in practice trickles down to increased R\&D efforts in the water sector. In the above context, this study takes an overview of existing water management practices in Bangladesh; and identifies the major challenges facing water management today. Further, the role of hydrological services is focused on, including the need for targeted R\&D.

\section{Water management and key issues for Bangladesh}

\section{A. Background}

Temporal and spatial distribution of rainfall in our country is highly skewed; with about $75 \%$ rains falling during three monsoon months in most parts of the country. Water resources are under increasing competition because of burgeoning population with increasing affluence demanding more water in the form of agriculture, industry, domestic and hydropower needs. Water management for the society today is very complex, and involves diverse activities that are administered by different players. Major components constituting present day water management are classified below:

1) Water allocation: Apportioning of water to major users and uses; maintaining minimum levels for social and environmental use, while addressing equity and development needs of society.

2) River basin planning: Preparing and updating the basin plan as per need by incorporating stakeholder views on development and management priorities for the basin.

3) Stakeholder participation: Implementing stakeholder participation as a basis for decision making that takes into account the best interests of society and the environment in the development and use of water resources in the basin.

4) Pollution control: Managing pollution using socially acceptable principles and appropriate incentives to mitigate environmental and social impacts.

5) Monitoring: Implementing effective monitoring systems, which provide needed management information to identify and respond to infringement of laws/ regulations/ permits.

6) Economic and financial management: Applying economic and financial tools for investment and cost recovery to support the goals of equitable access and sustainable benefits to society.

7) Information management: Providing essential data necessary to make informed and transparent decisions towards sustainable management of water resources.

\section{B. Existing practices}

The above-mentioned activities, generic to water management in the country, are beset with a number of challenges that put these services at risk. Bangladesh is undergoing rapid economic development and urbanization; with the current water development and management systems proving to be not sustainable. Lack of adequate storage is a major challenge in water resources development. Consequently, groundwater resources are being increasingly used, even to the 
extent of over-exploitation. Groundwater constitutes over half of Bangladesh's total water use; with $60 \%$ irrigated areas and $70 \%$ domestic water supply depending on groundwater. More than $15 \%$ of Bangladesh's food is estimated to be cultivated using non-renewable, mined groundwater. Water data are collected by different agencies in Bangladesh, and stored at varied locations, with no common umbrella available. This leads to difficulties in accessing all relevant data by employees in different departments. Some states make limited amounts of information available to the public; resulting in politicians, domestic, industrial and agricultural users not making optimal decisions due to a lack of information. This can exacerbate water resources issues. Another challenge is the disconnection between management of surface water and ground water. Experts/administrators in each field are usually located in different departments, with different management structures. Further, the data management tools used is often different for surface and ground water. For example, in Bangladesh the application software MIKE and HYMOS are used for surface water analyses; and GeoWin and GEMS for ground water. This makes it difficult for the state agencies to derive the most value from their water, with surface and ground water resources not considered together.

Apart from additional storage, there is an urgent need for improved management of water resources at all levels. ${ }^{3}$ Irrigation management is a case in point, where potentially large reduction in quantum of water use is feasible. A framework of agricultural, engineering and socio-economic measures is needed for effecting and efficient use of irrigation water supply. Agricultural measures include: deep cultivation, developing crops resistant water stress, improving soil moisture availability and staggering of water requirement for the crops. From socio-economic point of view, we need to see water as an economic good for which a rational price may need to be attached to protected water supply, similar on the lines of power supply. Further, users of irrigation water need to be protected by maintenance of an effective system of legally enforceable water-rights and other water-legislation. Engineering measures are simultaneously needed to be enforced for sustainability in irrigation water supplies. Such measures include: periodical risk analysis, integration of small reservoirs with major reservoirs to ensure that benefits are maximized, improving efficiency of water conveyance system by better operation and maintenance procedures including rehabilitation and modernization measures wherever warranted. This warrants planned implementation of lift irrigation schemes in association with canal-water supplies; and conjunctive use of surface and ground water helps in combating water-logging and Stalinization of farm-land.

\section{Need for hydrologic design aids and generic DSS models}

Skills and knowledge are built up in individuals through years of experience and 'on-the-job' training. Modelling expertise within states tends to be limited to a few individuals. This expertise allows water resources managers to operate their systems using engineering judgments, often based on a highly developed 'feel' for the situation. When managers want to run test scenarios for short-term planning or to test the feasibility of infrastructure projects, they are fully reliant on the skills of a few modelers available at that time. When key personnel are lost due to factors such as transfer and retirement, the expertise is often lost irretrievably. Individual managers and technicians who are entrusted with water management functions at central/ state/ other agency levels do generally a good job in operating often complex systems to deliver best services to a wide range of users. Good managers and technicians are no substitute for improving and systematizing water management practices through good, generic decision support system (DSS) models that can address issues such as providing access to common data; enhancing institutional 
capacity for decision making; publishing key data to inform the general public; and assisting short and long term planning through modeling ${ }^{4}$. DSS systems gainfully employed in water management include: simulation models for surface water planning, reservoir optimization with forecasted stream flows, drought monitoring/ assessment, flood forecasting and management and integrated water resources management. Section III.I.III details certain focused national efforts in this direction. One issue that irks water management in Bangladesh is the low use of data in design of projects. Very often, designs of projects are done by empirical/ rational methods. The principal reasons for this approach are: difficulties in accessing all relevant records, processing and analysis, absence of specialists such as hydrologists and hydro geologists in design offices and lack of established design aids.

\section{Water management issues}

Coupled with problems co-existing with present-day water management practices aforedescribed, modern-day water resources management is beset with the following key issues arising from the vagaries of hydrologic cycle and other extraneous factors. ${ }^{5}$

\section{Increasing vulnerability to severe events}

Inter-Governmental Panel on Climate Change (IPCC) highlights the potential for more frequent and more severe weather conditions; which is corroborated by many instances of extreme hydrological events. Such eventualities, coupled with increased pressure on land from the increasing population, will make safety of life and property high on the agenda for administrators and planners.

\section{Urban demand}

More than 60 percent of Bangladesh population is projected to live in urban and semi-urban areas by 2015 . People, and the ever-growing industrial sector, will demand an increasingly larger share of the total water available; much of which is liable to be diverted from water meant for irrigation; which in turn can place greater pressure on water supply systems, and reduce availability of arable land. Accelerated urbanization has also the potential to create substantial pollution load on freshwater supplies and estuaries, which needs to be addressed. With urbanization comes the problem of the less privileged in the society often flocking to flood plains of rivers, thus creating additional technological and socio-economic issues concerning flood management.

\section{Unrestricted extractions}

Often, there is neither a management plan nor restrictions on water extraction from scarce resources. Water being the ultimate 'commons', and since water resources are no longer boundless, communities need to study water systems and re-define wise use. ${ }^{7}$ Changes in human values, and ideas of morality, are needs of the day as regards water usage to avoid a situation where rational pursuit of individual self-interest can lead to collective ruin. Ground water extraction in large parts of Bangladesh is a classic example in this respect.

\section{Climate change}

In general, analyses and application of management techniques in water sector have all along been carried out based on the presumption that hydrological series are stationary. There is growing evidence of shifting trends in such series, which need to be assessed and ascertained to enable taking corrective actions as needed. Periodic review of hydro meteorological networks for 
arriving at optimum network also assumes significance in this respect, as brought out under Section III.I. There is growing evidence of warming climate, as spelt out by climatologists, which can spell misery to the population in such regions. IPCC warns that climate change is expected to exacerbate water scarcity situation in Asia, with consequential multiple socioeconomic stresses.

\section{Allocation problem of existing supplies}

A typical water-supply system to a city involves structures such as reservoirs, canals, pumping systems, pipes, etc.; which are generally designed and allocated on the basis of past availability and existing demands. The current and/ or future availability does not often form a part of the scheme of things. This makes many water supply systems over-allocated. Studies show that, in general, lower the data length, higher is the likelihood of over-estimating water resources availability in a region. Uncertainties in respect of flood potential assessment too increase. Such factors warrant review of allocation of water supply systems and safety aspects from flood hazards periodically. ${ }^{8}$

\section{Land-use changes}

Land use change is a reality, with more forest/ arid/ marshy/ fallow areas paving way for activities such as mining, agriculture, tourism-related activities and infrastructure development. For instance, a large number of mega power projects coming up on the eastern coastal region of Bangladesh. Expanding plantations and decreasing forest cover also play a major part in this scenario. Changes to land use, even within agricultural lands, have substantial implications for both water availability and use.

\section{Environmental requirements}

Environmental concerns are foremost on the minds of administrators, planners and the general populace; with the result that there is a steadily increasing awareness and emphasis on the requirements of environmental flows in any river system towards maintaining ecosystems such as wetland and in-stream environs. We have begun accepting the rights of nature, treating rivers, estuaries, forests and the like not as simply properties, but entities who have their own right to flourish. The day is not far of wherein this right would be put into statute, which would enable a vigilant citizen to file a suit on behalf of, say the injured watershed, arguing that its health is crucial to the common good. ${ }^{9}$ In the above context, the ensuing sections detail the wherewithal to counter the issues by sustained scientific and technological initiatives in the hydrological services regime.

\section{Hydrological services}

\section{A. Monitoring, analysis and assessment}

The value of information for sustainable water resources development is self-evident. Information is a product of basic data, operated upon by mathematical, statistical, hydraulic, hydrological and other optimization models. Specific information to be produced would depend on recognition of the problem, and its subsequent solution using the relevant model(s). If the database is well designed and the models well documented, the same data can produce different varieties of information, with each one capable of being used in different situations. Hydrological information system (HIS) forms the backbone of water resources activities for a 
country; providing reliable data for long-term planning, design and management of resources and water use systems, and for research activities in related areas. In Bangladesh, primary data for HIS are collected, processed, stored and status reports brought out by agencies such as BWDB, Bangladesh Meteorological Department (BMD), State Irrigation/ Agriculture/ Public Works/ Water Resources Departments, etc. HIS, in practice, comprises data collection and storing system, data communication/ transmission system, data transformation system for producing information and information communication system, which in turn leads to inputs to informed decision making by the end-users, as delineated below.

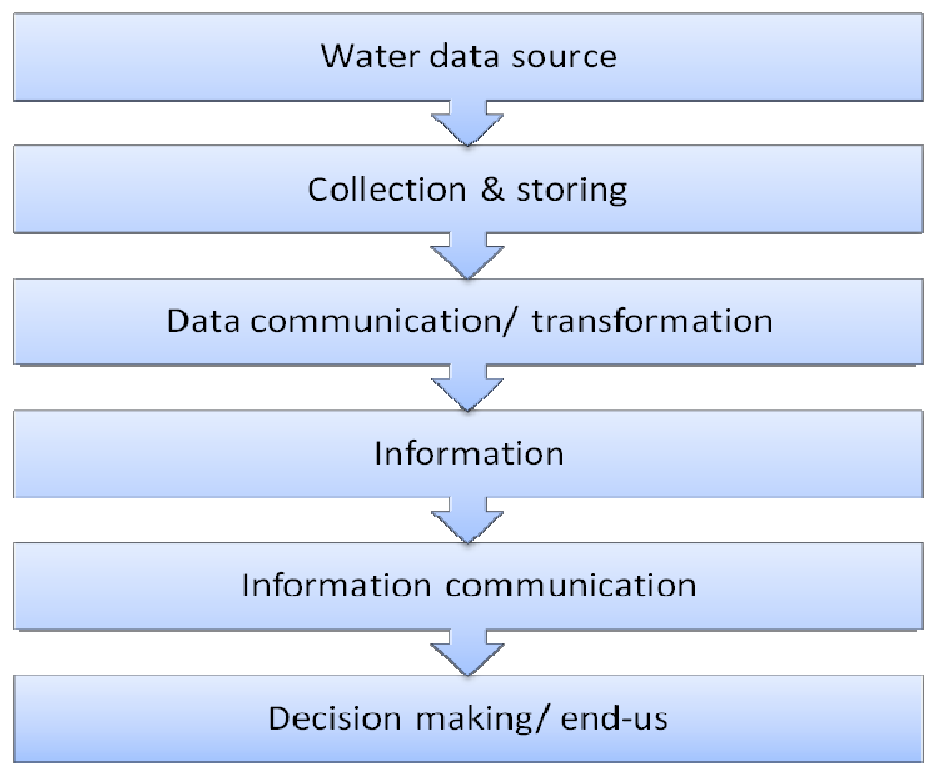

Figure 1. Hydrological information system (HIS).

Data transformation is in practice done by models, which can range from simple statistical models, hydrologic design aids, monograms, involved DSS models and the like. HIS is central to sustainable water development, with its output having a wide variety of users, both in the public services domain and in private sector. Users fall under the broad clusters of large scale and repeat users, and occasional or one-time users. A majority of the users in the public services domain belong to the former; whereas, most users in the private sector are likely to belong to the latter category. For instance BWDB,IWM,CEGIS are sophisticated users of water data; with the organization using data extensively in physical, mathematical, hydraulic, hydrologic and other models while conducting applied/ specific research studies pertaining to water resources. Large scale and repeat users of HIS mainly belong to various policy level and operational level government departments, financial institutions, command area development agencies, irrigation/ water resources departments, public works departments, NGOs, etc. Occasional users are of two types: those who need to find and use water in a micro-geographical area for their own use, and those who need to find and use water for commercial purposes or community activities.

\section{Hydrologic network}

The hydrological network includes subsystems for measuring stream flow, precipitation, groundwater, evaporation, etc.; and provides water-related data for HIS. Thus, for a river basin, the hydrometric network for measurement of stream flows forms a subsystem of the hydro 
meteorological network. Setting up and maintaining such a network is an evolutionary process, wherein a network is established early in the development of the geographical area. The network needs to be reviewed and upgraded periodically to arrive at the optimum network. Different approaches exist for optimization of a real life network, as delineated in Figure 2.

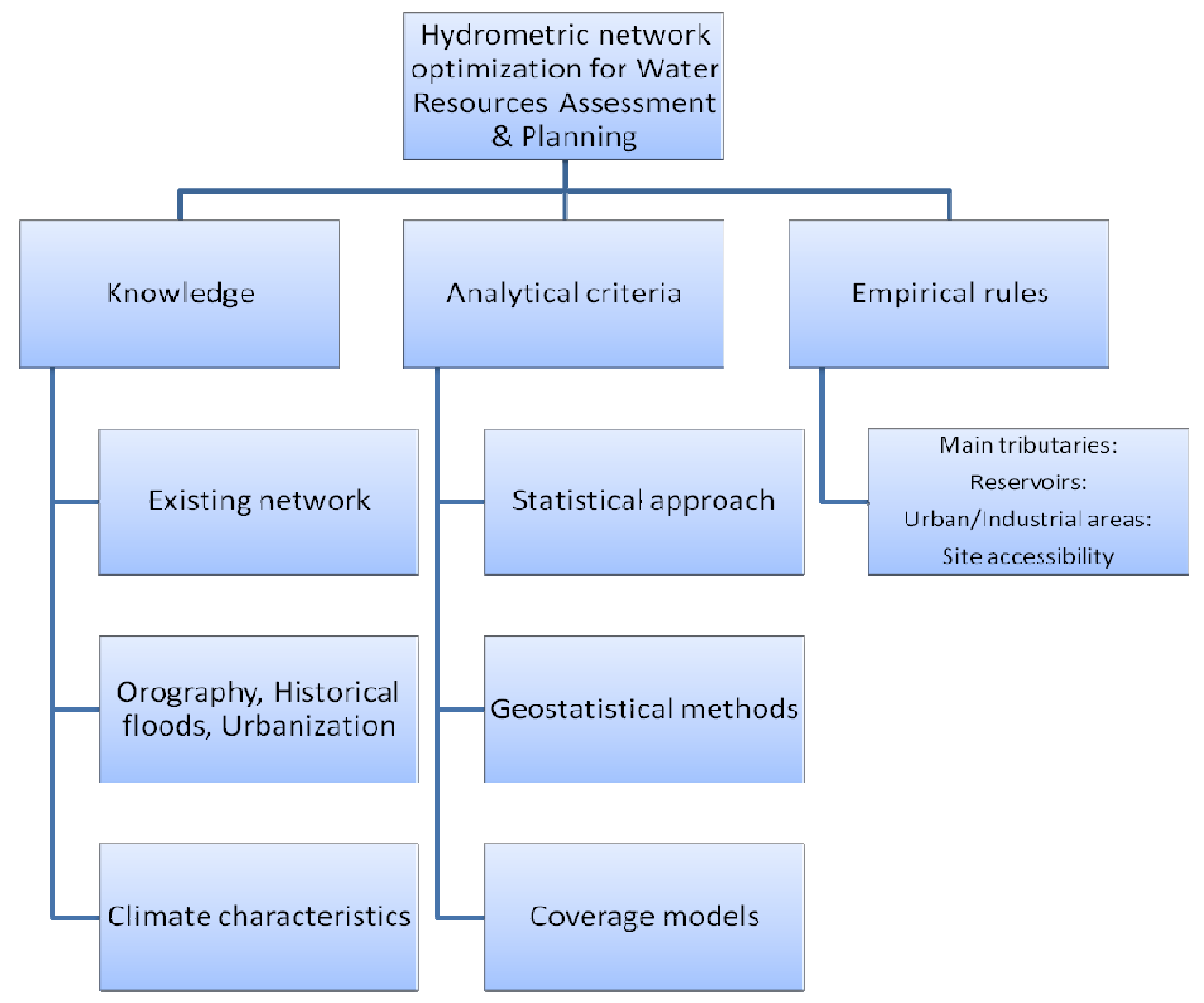

Figure 2.Approaches to network.

\section{Modelling capabilities}

A major challenge for future in water resources sector will be development of analytical and modeling techniques, which would enable holistic approach to resource management. Advances in modeling capacities are closely associated with advances in computers, and the interaction between modelers of hydrologic systems, programmers and hardware specialists. Hydrologists make use of GIS technology to integrate various data and applications into one manageable system. With a large number of water resources projects in different stages of planning and execution, the need for modeling skills is all the more pronounced, especially for hazard assessment. To usher in uniformity of approach among state and central agencies in water data dissemination, work is under way for development of standardized hydrological design aids (HDA) using well-established, internationally acceptable methodologies. HDA aims to provide a platform for simplifying and making more accurate a range of hydrological analysis tools and associated guidance for users across Bangladesh; and would facilitate and expedite hydrologic design and assessment of surface and ground water resources. 


\section{B. Products and services}

Collection of hydro-meteorological data using instruments, and transmitting them to wherever the data are needed for analysis and decision making, form an important component of HIS. Use of new products and services that are designed to enhance the quality and speed matters in water resources management applications. Short message service, internet, cloud computing and other future developments in these areas will be of vital interest. Acoustic Doppler Current Profilers (ADCPs) are established tools for water management in riverine and coastal environment, which are increasingly being used in Bangladesh. Likewise, Integrated Bathymetric System for Reservoir Sedimentation Survey (IBSRSS) makes it easier to carry out hydrographic survey of reservoirs.

Under IWM, BWDB upgraded the Current Meter Rating Trolley (CMRT), and refurbished the rating tank facility to meet current meter calibration requirements in accordance with the relevant national/ international standards. The upgraded CMRT is equipped with instruments based on state-of-the-art technology such as variable-speed servo motor drives with programmable logic controller for precise trolley speed control in the range of $0.01 \mathrm{~m} / \mathrm{s}$ to 6.0 $\mathrm{m} / \mathrm{s}$; and real-time data acquisition and processing system capabilities for current meter calibration.

\section{Research}

For each case involving water resources development and management, the optimal solution needs to be obtained and fine-tuned, to match site-specific conditions and user's expectations through R\&D. With the increasing demand on water resources, and an increased awareness of resultant environmental impact of conducting and operating physical works that alter natural flow regimes, more and more questions would routinely be raised during project formulation stages regarding the before and after comparison of proposed projects. For sustainable water resources development, topics like these, and numerous others, naturally become subjects of R\&D. Moreover, the intensity of external effects in water use is greater than in any other sector of the economy; which is why water resources have very often been a publicly managed or regulated resource. For the reasons above-mentioned, in Bangladesh, the magnitude of investment from the national exchequer in water resources is huge, calling for the use of best available technology to manage the investment; which translates to need for effective R\&D in the water sector. Water resources R\&D falls into three broad categories: basic, specific/ applied and action research. Basic research comprises investigations or studies of specific problems, which add to the theoretical knowledge that may or may not find immediate applications, but would definitely advance technology for future applications. Basic research also provides necessary inputs for applied research on specific problems. Specific/ applied research studies are those for finding appropriate solutions to the problems confronted by engineers in the field, based on the available research knowledge. Often, specific research is referred as applications. Applications can essentially be either 'works' or 'studies' carried out for specific purposes. Works may concern hydraulic and hydro-informatics investigations and design developments carried out and implemented. These also may be related to actions such as design and implementation of decision support systems, riverine water quality monitoring, real time flood forecasting systems etc. Action research includes studies on pilot projects, field problems, and those investigations relating to model prototype conformity to put available research results, to test, in order to assess their validity for practical applications. Holistically looking, sustainable water resources development is an integrated activity involving engineering and economic issues 
as well as resource policies. Water resources projects are sustainable, if water of sufficient quantity and quality is available, at acceptable prices, to meet the demands and quality standards of the population of the region now and in the future without causing the environment to deteriorate. Sustainability must be the concern of project planner and all engineers and scientists involved in the planning process of a water resources project. However, technical skills alone are not sufficient to make a system sustainable. Sustainability also requires a willingness to go beyond the scope of standard technical solutions, for which better understanding of the interaction of the system with its surroundings and with other uses is necessary.

\section{Conclusion}

Modern technology has contributed immensely to the sustenance of Bangladesh population at the present level. Water, through its development, conservation, control and protection enters into infrastructure in a big way. The key to sustainable water resources development in the country is effective use of innovative techniques in the sector, which in practice, translates to larger role for R\&D to find ways and means for tackling inefficiency and waste, both in delivering water-services and in responding effectively to water demand. Issues such as climate change, growing urban demand, land-use changes and environmental requirements continue to influence adversely sustainable water resources development and management. R\&D provides the underpinning for use of best available technology and optimum use of water resources. In the above context, this study has given an overview of the existing water management practices in the country, and identified the major challenges facing water resources management today. Such challenges include climate change, increased vulnerability due to extreme events, rising urban demand of water and consequential change in water dynamics, allocation problems relating to existing demands, unrestricted extraction of water resources and environmental requirements. Also elucidated is the role of hydrological services including focused $R \& D$ in resolving the varied issues. R\&D efforts in water sector are shown to assume two major roles in furthering sustainable water resources management: i) in helping to decrease the vulnerability by furthering development and increasing adaptive capacity, and ii) by giving an option to respond to numerous contingencies that an unknown future holds. In an information-based global economic system, all knowledge has potential economic value. However, in the modern-day information and communication technology led $\mathrm{R} \& \mathrm{D}$ era, universities, research centers and researchers are no longer in total control of the definition and production of knowledge; but are simply actors in a multi-sectorial social, political, scientific and technological enterprise. This augurs well for setting the ground for technical innovation in varied areas, especially water sector; where high technology is a historical necessity on account of the ever-burgeoning human population and consequential water demand.

\section{References}

1،"Water: Our thirsty world”, National Geographic, April, 2010.

${ }^{2}$ Bartholomewates, A., The story of water-Source of life, Floris Books, UK, 2010.

${ }^{3}$ Bangladesh - Water resources management sector review, Report on the irrigation sector, Rural Development Unit, World Bank in cooperation with MoWR, Government of Bangladesh, September, 1998. 
International Symposium for Next Generation Infrastructure October 1-4, 2013, Wollongong, Australia

4، Development of decision support system for integrated water resources development and management," Vols. I-III, NIH, Roorkee, June, 2011.

5"Hydrology for water management," Vols. 57, No. 3, WMO Bulletin, July 2008.

${ }^{6}$ Climate change and water, IPCC Technical Paper VI, WMO, June 2008.

${ }^{7}$ Vivekanandan N., and Mathew F.T., "Optimisation of hydrometric network using entropy method," Bangladeshn Journal of Power and River Valley Development, Vol. 61, No. 9-10, 2011, pp. 154-158.

${ }^{8}$ Development of hydrologic design aids (SW) under HP II, State-of-the-art report, CWC, MoWR, July, 2010. 